\title{
Podophyllin (10\%) Ointment: A New Therapeutic Modality for Psoriasis
}

\author{
Khalifa E. Sharquie $^{1 \#}$, Adil A. Noaimi ${ }^{2}$, Wesal K. Al-Janabi ${ }^{3}$ \\ ${ }^{1}$ Scientific Council of Dermatology \& Venereology, Iraqi Board for Medical Specializations, Department of Dermatology \& \\ Venereology, College of Medicine, University of Baghdad, Baghdad, Iraq; ${ }^{2}$ Department of Dermatology \& Venereology, College of \\ Medicine, University of Baghdad, Baghdad, Iraq; ${ }^{3}$ Department of Dermatology and Venereology, Baghdad Teaching Hospital, \\ Baghdad, Iraq. \\ Email: "ksharquie@ymail.com, adilnoaimi@yahoo.com,drwesalaljanabi@yahoo.co.uk
}

Received August 25 $5^{\text {th }}, 2013$; revised September $23^{\text {rd }}, 2013$; accepted October $30^{\text {th }}, 2013$

Copyright (C) 2013 Khalifa E. Sharquie et al. This is an open access article distributed under the Creative Commons Attribution License, which permits unrestricted use, distribution, and reproduction in any medium, provided the original work is properly cited.

\begin{abstract}
Background: There are many topical therapies for the treatment of plaque psoriasis like steroid, dithranol, tar and vitamin D analogues, but none of them is ideal. Most recently, in a pilot study, podophyllin 5\% ointment on every other day regimen was as effective as clobetasole $0.05 \%$ ointment twice daily. Objective: To reassess the efficacy of a higher concentration of podophyllin $(10 \%)$ in the treatment of mild psoriasis in comparison with clobetasole using a different regimen. Patients and Methods: This is therapeutic, comparative, placebo-controlled study conducted at the Department of Dermatology-Baghdad Teaching Hospital, during the period of January 2011 - October 2012. Eighty-seven patients with mild plaque-type psoriasis were divided into three groups: Group A (30) patients were treated with podophyllin 10\% ointment; Group B (30) patients were treated with clobetasol propionate $0.05 \%$ ointment and Group C (27) patients were treated with Vaseline as a placebo control group. All patients were treated on every other day. The efficacy was evaluated every 2 weeks for 8 weeks using PASI score and the local and systemic side effects were recorded. The relapse was recorded after cessation of therapy in those patients who achieved good response during another 8 weeks follow-up period. Results: The patients were 60 (68.9\%) males and 27 (31.1\%) females (male: female ratio, 2.2:1). Their ages ranged from $18-62(36.4 \pm 10)$ years. Their disease duration ranged from $0.1-40(7.8 \pm 8.5)$ years. Their baseline PASI score ranged from $1.6-9.6(4.4 \pm 5.85)$. At the end of $8^{\text {th }}$ week of therapy, Group $A$ patients had achieved much higher reduction in PASI score $(77.4 \pm 14.1)$ than Group B patients $(60.4 \pm 27.8), \mathrm{P}$ value $=0.004$, and both of them were with statistically and significantly higher PASI reduction than patients in Group $C(28 \pm 23.4)$, P value $=<0.001$. The total relapse rate during 8 weeks follow-up was much lower among Group $A$ treated patients, $20 \%$ versus $66.6 \%$ in Group B (P-value $=0.002$ ), while the relapse rate was $100 \%$ in the Group C patients. Regarding side effects: $3(10 \%)$ patients developed erythema, burning, pain, blistering and hypopigmentationin Group A. No side effects were reported in Groups B nor C patients with no statistically significant difference among the three groups $(\mathrm{P}=$ 0.052). Conclusion: Podophyllin $10 \%$ ointment was more effective than clobetasole $0.05 \%$ ointment on every other day treatment regimen at the end of 8 weeks treatment with no side effects and a much lower relapse rate in treatment of mild plaque-type psoriasis.
\end{abstract}

Keywords: Podophyllin; Psoriasis; Iraqi Patients; Every Other Day Therapy

\section{Introduction}

Psoriasis is a common dermatological disease whose aetiology is multifactorial, but the immune theory is the most established one. Treatment of psoriasis depends on its severity which could be topical or systemic. Topical

*Disclosure: This study is an independent study and not funded by any drug company.

${ }^{\#}$ Corresponding author. corticosteroid is commonly prescribed in psoriasis, but frequently associated with many side effects especially on long term use with high relapse rate. Dovonex and dovobet had also been used but with less encouraging results, and less side effects than topical corticosteroids $[1,2]$.

Podophyllin, an alcoholic plant extract obtained from dried rhizomes of common plants called emodi (Indian 
podophyllum) or podophyllumpeltatum (May apple or Mandrake) [3]. Podophyllun resin contains many active ingredients that work through multiple actions mainly by arresting mitosis and differentiation, blocking oxidation enzymes in tricaboxylic acid cycle and thus interfering with cell nutrition, inhibiting axonal transport, protein, RNA, and DNA synthesis and affecting mitochondrial activity with reducing cytochrome oxidase activity [4]. Podophyllin had been used over a long time for the treatment of viral warts with possible side effects if it's used on large area [3], and also been used in treatment of genital warts in infants with no noticeable side effects [5]. Recently, podophyllin $25 \%$ had been used as effective therapy for cutaneous leishmaniasis [6] and basal cell carcinoma [7,8]. Most recently podophyllin $25 \%$ solution had been used in treatment of genital warts in pregnant women with no reported side effects in mothers and infants for one year follow-up [9]. Those studies encouraged us to conduct a pilot study for the treatment of 62 patients with mild plaque psoriasis and the results were very promising [10]. In that study, at the end of 8 weeks treatment, podophyllin 5\% ointment on every other day was found to be as effective as clobetasole $0.05 \%$ ointment twice daily with no local or systemic side effects and with a much lower relapse rate.

Therefore the objective of the present work is to perform a further study to re-evaluate the efficacy and safety of a higher concentration of podophyllin $(10 \%)$ in comparison with clobetasole and Vaseline with all being used on every other day based regimen.

\section{Patients and Methods}

This is therapeutic, comparative, single-blind, placebocontrolled study was carried out at the Department of Dermatology and Venereology, Baghdad Teaching Hospital, during the period from July 2011 to October 2012.

The nature and target of this study were explained for each patient. Formal consent was taken from each patient before starting the therapy, after full explanation about the nature of the disease, course, and the options of treatment, follow up, prognosis, complications and the need for pre and post treatment photographs. Also, the ethical approval was given by the scientific committee of the Scientific Council of Dermatology \& VenereologyIraqi Board for Medical Specializations.

Inclusion criteria: Mild plaque- type psoriasis which is defined as PASI score of less than 10.

Exclusion criteria: making use of history, physical examination and investigations, the following population were excluded: pregnant or lactating women, patients younger than 18 years, those with hepatic, renal, haematological or other systemic disorders, immunosuppression, diabetes mellitus, peripheral neuropathy, poor peripheral circulation, patients with lesions on the follow- ing sites: Scalp, face, acral parts, hands and feet, intertriginous and anogenital areas. Patients with pustular and guttate psoriasis were also excluded.

The diagnosis was established on clinical basis, and the patients were not taking any topical nor systemic psoriasis treatment for at least 3 months prior to starting the treatment. History was taken regarding: gender, age, and age of onset, duration of disease and presence of itching. Physical examination was done to assess the site, surface area and severity of psoriasis using PASI score. A total of 98 patients with mild plaque-type psoriasis were evaluated but only 87 patients completed the study (both the treatment and follow up period). The patients defaulted for many reasons mainly transport and security reasons. They were divided into three groups according to their treatments model:

Group A: Thirty patients treated with podophyllin 10\% ointment every other day. Podophyllin 10\% ointment was prepared by mixing $10 \mathrm{~g}$ of podophyllum resin powder (purchased from Merck Company, Germany) with up to 100 grams Vaseline kept in a plastic container at room temperature in the hospital. Patients were instructed to apply a thin layer of podophyllin preparation on the psoriatic plaque, avoiding the surrounding normal skin, with the use of disposable nylon gloves and to wash off the area with water and soap after 6 hours (Figure 1).

Group B: Thirty patients treated with clobetasole propionate $0.05 \%$ ointment [manufactured by the State Company for Drug Industries and Medical Appliances Nineveh-Iraq (NDI) under licence of SDI Co.] in unlabelled tube.

Group C: Twenty seven patients treated with Vaseline only (manufactured by Anglo-Dutch Company Unilever) kept in a plastic container at room temperature in the hospital.

All patients in the three groups were treated on every other day. Patients were assessed at 5 visits during the treatment period: at week zero, week 2, week 4, week 6 and week 8 to record the clinical response, cure and any local or systemic side effects. After the cessation of treatment, all patients were followed up every 4 weeks for another 8 weeks during which relapse and any local or systemic side effects were recorded.

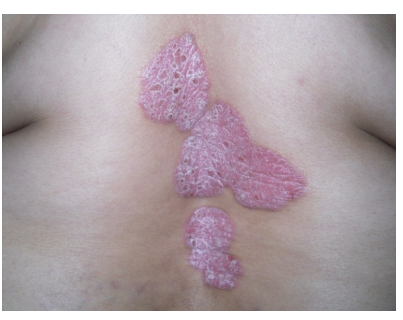

(a)

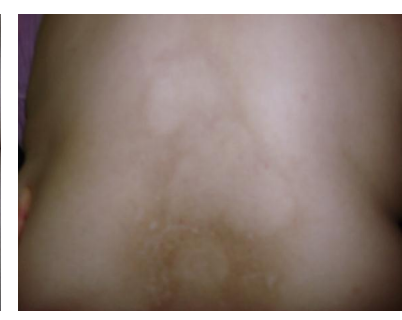

(b)
Figure 1. Forty years old female patient treated with podophyllin: (a) Before treatment; (b) After 5 weeks treatment. 
Patients were screened to record any systemic podophyllin side effects by clinical assessment and by doing the following investigations before, during and after treatment: general urine examination, complete blood picture, erythrocyte sedimentation rate, liver and renal function tests, serum electrolytes, fasting blood sugar, and serum amylase and serum lactate dehydrogenase.

\subsection{Efficacy Evaluations}

Pre, during and post treatment photographs were taken using Sony-digital, high sensitivity ISO 1600, 10.1 mega pixels, DSC-N2 optical steady shot camera, in the same place with fixed illumination and distance.

Assessment of drug efficacy was based on the reduction of PASI score. Patients were considered as good responders if the reduction in PASI score was $50 \%$ or more [11], partial responders if the reduction in PASI score was $25 \%-49 \%$ and poor responders if the reduction in PASI score was $<25 \%$ [12]. Complete clearance was considered when there was a reduction in PASI score of $\geq 90 \%$. Relapses defined as loss of $50 \%$ of PASI improvement from baseline in patients who achieved at least 50\% reduction in PASI score [13].

\subsection{Statistical Analysis}

SPSS v.18 (statistical package for social sciences version 18) used for data input and analysis. Continuous variables presented as mean \pm SD (standard deviation) and discrete variables presented as numbers and percentages. Chi square test for independence is used to test the significance of association between discrete variables. For testing the significance in means between more than two samples; ANOVA test \& Kruskal Wallis test are used as appropriate for independent samples and Friedman test used for related samples. For testing the significance of difference in means between two samples; Wilcoxon rank test used to test the significance of difference in means between tow related samples or in any place where the normality of distribution in question. Turkey HD test used to test the significance of difference between means of two independent samples as a complementary test after ANOVA test looking for the exact significance of difference between two means. For testing the significance of observed difference in means of two normally distributed continuous variables; $t$ test for two independent samples was used. Findings with $\mathrm{P}$ value less than 0.05 were considered significant.

\section{Results}

A total of $\mathbf{8 7}$ patients with mild plaque-type psoriasis who completed the study were evaluated during both the treatment and follow up period. They were 60 (68.9\%) males and 27 (31.1\%) females, with: male: female ratio
2.2:1. Their ages ranged from $18-62$ years with a mean \pm SD of $36.4 \pm 10$ years. The newly diagnosed cases were $27(31 \%)$ patients. The disease duration ranged from 0.1 - 40 years with a mean $\pm \mathrm{SD}$ of $7.8 \pm 8.5$ years and their age at onset ranged from 5 - 55 years with a mean $\pm \mathrm{SD}$ of $28.5 \pm 12.9$ years. Itching was positive in $42(67.7 \%)$ cases. The family history was positive in 35 (40.2\%) cases.

Their baseline PASI score ranged from 1.6 - 9.6 with a mean $\pm \mathrm{SD}$ of $4.4 \pm 5.85$. There was no statistically significant difference in the demographic features among the three groups. The location of treated psoriatic plaques in the three groups was shown in Table 1.

1. Group A: they were $21(70 \%)$ males and $9(30 \%)$ females with a male to female ratio of $2.3: 1$, their ages ranged from $18-62$ years with a mean \pm SD of $35 \pm 12.6$ years. The newly diagnosed cases were 10 (33.3\%) patients. Their disease duration ranged from 0.3 - 31 years with a mean \pm SD of $7.5 \pm 9.1$ years and their age at onset ranged from 6 - 52 years with a mean \pm SD of $27.4 \pm$ 11.2 years. Itching was positive in $19(63.3 \%)$ cases. The family history was positive in $10(33.3 \%)$ cases. Their baseline PASI score ranged from 1.6 - 9.4 with a mean \pm $\mathrm{SD}$ of $5.1 \pm 2.8$ was reduced to a range of $0-7.1$ with a mean \pm SD of $1.2 \pm 0.9$ after 8 weeks of treatment, this reduction in PASI score was statistically highly significant with $\mathrm{P}$-value $=<0.001$.

2. Group B: they were $21(70 \%)$ males and $9(30 \%)$ females with a male to female ratio of $2.3: 1$, their ages ranged from 20 - 60 years with a mean \pm SD of $37.2 \pm$ 11.4 years. The newly diagnosed cases were $9(30 \%)$ patients. Their disease duration ranged from 0.1 - 40 years with a mean \pm SD of $8.3 \pm 8.8$ years, their age at onset ranged from 5 - 55 years with a mean \pm SD of 28.8 \pm 13.9 years. Itching was positive in $18(60 \%)$ cases. The family history was positive in $13(43.3 \%)$ patients. Their baseline PASI score ranged from 1.7 - 9.6 with a mean \pm $\mathrm{SD}$ of $4.9 \pm 2.7$ was reduced to a range of $0-9.6$ with a mean $\pm \mathrm{SD}$ of $2.5 \pm 3$ after 8 weeks of treatment, this reduction in PASI score was statistically highly signifi-

Table 1. The location of treated psoriatic plaques.

\begin{tabular}{ccccc}
\hline Site & $\begin{array}{c}\text { Group A } \\
\text { N (\%) }\end{array}$ & $\begin{array}{c}\text { Group B } \\
\mathbf{N}(\%)\end{array}$ & $\begin{array}{c}\text { Group C } \\
\mathbf{N}(\%)\end{array}$ & $\begin{array}{c}\text { Total } \\
\mathbf{N}(\%)\end{array}$ \\
\hline Arms & $2(6.6)$ & $6(20)$ & $3(11.11)$ & $11(12.64)$ \\
Forearms & $16(53.33)$ & $12(40)$ & $18(66.66)$ & $46(52.87)$ \\
Trunk & $29(96.66)$ & $27(90)$ & $26(96.29)$ & $81(93.1)$ \\
Buttock & $4(13.33)$ & $3(10)$ & $3(11.11)$ & $10(1.14)$ \\
Thighs & $10(33.33)$ & $9(30)$ & $12(44.44)$ & $31(35.63)$ \\
Legs & $27(90)$ & $24(80)$ & $23(85.18)$ & $74(85.05)$ \\
$\mathbf{N}$ & 30 & 30 & 27 & 87 \\
\hline
\end{tabular}


cant with P-value $=<0.001$

3. Group C: they were $18(66.7 \%)$ males and $9(33.3 \%)$ females with a male to female ratio of $2: 1$, their ages ranged from $20-61$ years with a mean $\pm \mathrm{SD}$ of $37 \pm 12.1$ years. The newly diagnosed cases were $8(29.6 \%)$ patients. Their disease duration ranged from $0.2-30$ years with a mean \pm SD of $7.5 \pm 7.8$ years, their age at onset ranged from 6 - 55 years with a mean \pm SD of $29.4 \pm$ 13.9 years. Itching was positive in $9(33.3 \%)$ cases. The family history was positive in $12(44.4 \%)$ cases. Their baseline PASI score ranged from $2-9.6$ with a mean \pm SD of $4.9 \pm 2$ was reduced to a range of $0.3-8.8$ with a mean \pm SD of $3.5 \pm 1.9$ after 8 weeks of treatment, this reduction in PASI score was statistically significant with P-value $=<0.001$.

In each group the patients were subdivided into 3 groups according to their response to treatments as follow (Tables 2 and 3): Group A, All patients, 30 (100\%), achieved good response. Group B, patients who achieved good response were $21(70 \%)$ patients, patients with partial response were $6(20 \%)$ patients and patients who achieved poor response were $3(10 \%)$ patients. Group $C$, patients who achieved good response were 3 (11.2\%) patients, with partial response were 12 (44.4\%) patients while those with poor response were 12 (44.4\%) patients.

At the end of 8 weeks of treatment, Group A achieved a good response ( $\geq 50 \%$ PASI reduction) in all of cases $30(100 \%)$ and the patients start to notice improvement after 4 weeks of treatment (Table 4). On the other hand, Group B achieved a good response in about $21(70 \%)$ of cases, but the onset of action seemed to be slow as the improvement becomes clinically evident at 6 weeks of treatment. This difference was statistically significant, $100 \%$ versus $70 \%$ (P-value $<0.004$ ), Table 3, and both of them achieved a statistically significantly higher percentage of patients with good response than Group $C$, $11.2 \%, \mathrm{P}$ value $=<0.001($ Tables 2 and $\mathbf{3})$.

The difference in the percentage of patients who achieved complete clearance (PASI reduction $\geq 90 \%$ ) between Group A and Group B treated patients was statistically not significant, $16.7 \%$ and $20 \%$ respectively $(\mathrm{P}$-value $=1.000)$, Table 2, while no complete clearance was recorded in Group C.

The mean PASI reduction (mean $\pm \mathrm{SD}$ ) at different weeks of treatment for different groups (Table 4) was as follow: Group A, the mean reduction in PASI score was $41.3 \pm 23.1,53.2 \pm 22.4,68.4 \pm 14$ and $77.4 \pm 14.1$ after 2, 4, 6 and 8 weeks of treatment respectively. Group B, the mean reduction in PASI score was $32.2 \pm 21.9,40.8$ $\pm 24.9,52.6 \pm 25.4$ and $60.4 \pm 27.8$ after 2, 4, 6 and 8 weeks of treatment respectively. Group C, the mean reduction in PASI score was $32.2 \pm 26,32.6 \pm 19.7,30.9 \pm$ 19.8 and $28 \pm 23.4$ after $2,4,6$ and 8 weeks of treatment respectively.

When the speed of recovery was compared between Group A and Group B, the study showed no statistically significant difference at 2 weeks of therapy $(\mathrm{P}$-value $=$ 0.123 ), but with much quicker action in Group $A$ at 4, 6 and 8 weeks of treatment with P-values of $0.047,0.004$, 0.004 respectively (Table 4). However, the difference in the mean PASI reduction between Group A $(77.4 \pm 14.1)$ and group C $(28 \pm 23.4)$ after 8 weeks of treatment was statistically significant with P-value $=<0.001$ (Table 4). At the end of $8^{\text {th }}$ week of therapy, Group A was found to achieve much higher reduction in in PASI score (mean \pm SD, $77.4 \pm 14.1)$ than Group B $(60.4 \pm 27.8)$ treated patients and this difference was statistically significant $(\mathrm{P}$ value $=0.004)($ Table 5$)$ and both of them were with statistically significantly higher PASI reduction (mean \pm SD) than patients with Group C, $77.4 \pm 14.1$ and $60.4 \pm$ 27.8 versus $28.0 \pm 23.4, \mathrm{P}$ value $=<0.001$ (Table 4 ).

The relapse rate in patients with good response was as follow:

Group A, six (20\%) patients relapsed after 8 weeks of stopping treatment. Group B, seven $(33.3 \%)$ patients relapsed during the first 4 weeks after cessation of treatment and $7(33.3 \%)$ patients relapsed after 8 weeks of stopping treatment. The total relapse rate was found in 14 $(66.6 \%)$ of cases.

Group C, three (100\%) patients relapsed during the first 4 weeks after cessation of treatment.

The total relapse rate during 8 weeks follow up was much lower among Group A, 20\% versus $66.6 \%$ in Group $B$, which was statistically significant P-value $=$ 0.002. On the other hand Group $C$ had a relapse rate of

Table 2. Response to total course of treatment according to type of treatment.

\begin{tabular}{|c|c|c|c|c|c|}
\hline \multirow{2}{*}{ Treatment Category } & \multicolumn{5}{|c|}{ Response to Treatment } \\
\hline & $<25 \%$ & $25 \%-49 \%$ & $50 \%-74 \%$ & $75 \%-89 \%$ & $\geq 90 \%$ \\
\hline Group A N (\%) & l & / & $4(13.3)$ & $21(70)$ & $5(16.7)$ \\
\hline Group B N (\%) & $3(10)$ & $6(20)$ & $10(33.3)$ & $5(16.7)$ & $6(20)$ \\
\hline Group C N (\%) & $12(44.4)$ & $12(44.4)$ & l & $3(11.1)$ & l \\
\hline$P$ value $=<0.001$ & & & & & \\
\hline
\end{tabular}


Table 3. Degree of response in different groups.

\begin{tabular}{cccccccc}
\hline \multirow{2}{*}{ Response } & \multicolumn{2}{c}{ Group A } & \multicolumn{2}{c}{ Group B } & \multicolumn{2}{c}{ Group C } & \multirow{2}{*}{ P-value } \\
\cline { 2 - 6 } & No. & $\%$ & No. & $\%$ & No. & $\%$ & \\
\hline Good & 30 & $100 \%$ & 21 & $70 \%$ & 3 & $11.2 \%$ & $<\mathbf{0 . 0 0 1}$ \\
Partial & $/$ & $/$ & 6 & $20 \%$ & 12 & $44.4 \%$ & $<\mathbf{0 . 0 0 1}$ \\
Poor & $/$ & $/$ & 3 & $10 \%$ & 12 & $44.4 \%$ & 0.641 \\
Total & 30 & $100 \%$ & 30 & $100 \%$ & 27 & $100 \%$ & \\
\hline
\end{tabular}

*Good response cases with PASI score reduction $\geq 50 \%$. Partial response cases with PASI score reduction $25 \%-49 \%$. Poor response cases with PASI score reduction $<25 \%$.

Table 4. Reduction in PASI score (mean \pm SD) at different weeks for different groups.

\begin{tabular}{|c|c|c|c|c|c|}
\hline \multirow{2}{*}{$\begin{array}{c}\text { Treatment } \\
\text { Category } \\
\text { Total } \\
\mathbf{n}=87\end{array}$} & \multicolumn{4}{|c|}{ Reduction in PASI score (mean \pm SD) } & \multirow{2}{*}{ P-value } \\
\hline & 2 weeks & 4 weeks & 6 weeks & 8 weeks & \\
\hline $\begin{array}{c}\text { Group A } \\
(\mathbf{n}=\mathbf{3 0})\end{array}$ & $41.3 \pm 23.1$ & $153.2 \pm 22.4$ & $68.4 \pm 14$ & $77.4 \pm 14.1$ & $<0.001$ \\
\hline $\begin{array}{c}\text { Group B } \\
(\mathbf{n}=\mathbf{3 0})\end{array}$ & $32.2 \pm 21.9$ & $90.8 \pm 24.9$ & $52.6 \pm 25$ & $460.4 \pm 27.8$ & $<0.001$ \\
\hline $\begin{array}{c}\text { Group C } \\
(n=27)\end{array}$ & $32.2 \pm 26$ & $32.6 \pm 19.7$ & $30.9 \pm 19.8$ & $828.0 \pm 23.4$ & 0.500 \\
\hline P-value & 0.238 & 0.003 & $<0.001$ & $<0.001$ & \\
\hline
\end{tabular}

$100 \%$.The difference in relapse rate between the three modalities of treatments was statistically significant with p-value $<0.001$.

The following local side effects were recorded: three $(10 \%)$ patients developed erythema $3(10 \%)$, burning 2 (6.7\%), pain2 (6.7\%) and blistering $2(6.7 \%)$, where only the latter side effect necessitate temporary discontinuation of application for few days, and hypopigmentation1 (3.3\%) in Group A. No side effects were reported in Groups $B$ or $C$ with no statistically significant difference among the three groups $(\mathrm{P}=0.052)$.

Neither staining, unpleasant odour nor systemic side effects were reported. No systemic side effects were reported.

\section{Discussion}

Podophyllum resin contains several cytotoxic compounds in unpredictable ratio, [14] at least 16 active physiological compounds, including podophyllotoxin, picropodophyllin, $\alpha$ and $\beta$ pellatins, podophyllotoxone and 6methoxy podophyllotoxin, kampherol and quercetin. [3] Of these podophyllotoxin is the major active constituent that is a lipid soluble compound which easily crosses cell membrane [15].

The current work showed that podophyllin $10 \%$ ointment was more effective than clobetasole $0.05 \%$ oint- ment on every other day use. All the results of the present work were much better than the results of the pilot study [10]. So this study highly encourages every other day regimen probably to save time and money and insure better patient compliance (Table 5).

The speculated mechanism of action of podophyllin in psoriasis could include the antimitotic effect, arrest of cell differentiation and blocking of oxidizing enzymes.

Of interest podophyllin ointment had been showed no change in color, odors nor texture when it was kept in at room temperature after 8 weeks of preparation and use. This could probably be attributed to the occlusive properties of Vaseline providing beneficial expanded longer shelf life to podophyllin.

In comparison with other studies using daivobet ointment, podophyllin $10 \%$ ointment induced a higher percentage of good response ( $\geq 50 \%$ PASI reduction) $100 \%$ than that of daivobet (74.4\%) [16] and a higher percentage of patients with PASI reduction of $\geq 75$ (87.6\% vs. $19.7 \%$ in daivobet) [17]. Also, daivobet has problems of burning, stinging and irritation in up to $20 \%$ of patients $[1,18]$ and seldom clears plaques of psoriasis [1,19] with potential risk of hypercalcaemia [1].

Podophyllin and dithranol had some features in common as both are plant derived crude compounds, acting through inhibiting cell proliferation and affecting oxidizing enzymes involved in mitochondrial function and cell nutrition $[4,20]$. In a thrice weekly trial of short contact dithranol treatment, the mean PASI reduction was $82.3 \%$ which is very close to the present work results of $77.4 \%$ with podophyllin. Although in that study 6 out of 8 patients achieved a clearance of $90 \%$ or more with dithranol in comparison to $16.7 \%$ with podophyllin in the present work, but the drawback was using only 8 patients treated with dithranol [21]. In a previous Iraqi study, dithranol on daily treatment, had resulted in a relapse of $29 \%$ at 12 weeks which was close to that of podophyllin $(20 \%)$ at 8 weeks follow up in the present study [22]. In addition, staining of skin, clothes, hair and nails is common with dithranol $(100 \%)$ and the relative impracticality of dithranol had led to a decline in its use particularly for outpatients [1].

Five percent liquor carbonis detergens (LCD) in an emollient base resulted in a mean improvement of $48.7 \%$ by 4 weeks of daily based treatment [23] versus $77.4 \%$ mean PASI reduction by 8 weeks with alternate day podophyllin in the present work. While podophyllin achieved higher mean PASI reduction $(77.4 \%$ vs. $66.6 \%)$ than crude coal tar with a lower relapse rate $20 \%$ versus $61 \%$ [22]. Staining, folliculitis, unwelcome smell and appearance are well known common side effects of tar [2].

In comparison with $10 \%$ and $5 \%$ zinc sulphate cream, podophyllin achieved a higher good response in $100 \%$ of 
Table 5. Results summary of the pilot and the present studies.

\begin{tabular}{ccccc}
\hline Treatment category & $\begin{array}{c}\text { Podophyllin 5\% } \\
(\mathbf{N}=\mathbf{2 1})\end{array}$ & $\begin{array}{c}\text { Podophyllin 10\% } \\
\mathbf{( N = 3 0 )}\end{array}$ & $\begin{array}{c}\text { Clobetasole twice daily } \\
(\mathbf{N}=\mathbf{2 0})\end{array}$ & $\begin{array}{c}\text { Clobetasole every other day } \\
(\mathbf{N}=\mathbf{3 0})\end{array}$ \\
\hline Good response N (\%) & $20(95.3)$ & $30(100)$ & $14(70)$ & $21(70)$ \\
Complete clearance N (\%) & $2(9.5)$ & $5(16.7)$ & $13(65)$ & $6(20)$ \\
PASI reduction mean \pm SD at 8 weeks & $66.3 \pm 20.7$ & $77.4 \pm 14$ & $68.1 \pm 34.2$ & $60.4 \pm 27.8$ \\
Relapse N (\%) & $5(25)$ & $6(20)$ & $9(70)$ & $14(66.6)$ \\
\hline
\end{tabular}

patients after 8 weeks treatment versus. $60 \%$ and $53.8 \%$ after 12 weeks of treatment respectively with the onset of action seemed to be quicker with podophyllin as with zinc the patients started to notice improvement after 8 weeks of treatment with each concentration of cream versus 4 weeks in podophyllin. The relapse rate in podophyllin treated patients was much lower $(20 \%)$ than that of $10 \%$ and $5 \%$ zinc sulphate creams $77.8 \%$ and $85.7 \%$ respectively. Also the side effects were much lower (10\%) vs. $30.76 \%$ and $40 \%$ respectively [24].

In comparison with tazarotene, $0.05 \%$ or $0.1 \%$ gel applied once daily for 3 months showed $50 \%$ or greater improvement in $65 \%$ of patients [25], podophyllin was better with good response achieved in $100 \%$ of patients. In other study using tazarotene gel $0.05 \%$, the percentage of patients with PASI reduction of $\geq 75$ after 6 weeks of treatment was $45 \%$ [26] versus $87.6 \%$ after 8 weeks treatment with podophyllin in the present study.

\section{Conclusion}

In conclusion, this study has confirmed that podophyllin ointment is a new effective therapy for mild plaque-type psoriasis, and is more effective than other therapies including clobetasole with a lower relapse rate and without side effects.

\section{REFERENCES}

[1] C. E. M. Griffith and J. N. W. N. Barker, "Psoriasis," In: T. Burns, S. Breathnach, N. Cox and C. Griffiths, Eds., Rook's Textbook of Dermatology, 8th Edition, WileyBlackwell Publishing Company, Singapore, 2010, pp. 871-930.

[2] E. G. Johann and T. E. James, "Psoriasis,” In: K. Wolf, L. A. Goldsmith, S. I. Katz, B. A. Gilchrest, A. S. Paller and D. J. Leffell, Eds., Fitzpatrick's Dermatology in General Medicine, 7th Edition, Mc Graw Hill, New York, 2008, pp. 169-193.

[3] E. C. Martin, L. Christy, M. C. Cowan, S. W. Marshal, A. H. Dawson, S. A. Seifert, W. S. Schon, L. Yip, D. C. Keyes, K. M. Hurlbut and R. C. Erdman Arm Dart, "Medical Toxicology," 3rd Edition, Walters Kluwer Company, Philadelphia, 2004, pp. 1690-1701.

[4] D. G. Olsen and R. C. Dart, "Skin and Mucous Membrane Agents," In: Medical Toxicology, 3rd Edition, Wal- ters Kluwer Company, Philadelphia, 2004, pp. 1003-1004.

[5] K. E. Sharquie, M. M. Al-Waiz and A. A. Al-Nuaimy, "Condylomata Acuminate in Infants and Young Children. Topical Podophyllin Is an Effective Therapy," Saudi Medical Journal, Vol. 26, No. 3, 2005, pp. 502-503.

[6] K. E. Sharquie, A. A. Noaimi and A. G. Al-Ghazzi, "Treatment of Cutaneous Leishmaniasis by Topical 25\% Podophyllin Solution (Case-Controlled Study)," Thesis, Iraqi Board for Medical Specializations in Dermatology and Venereology, Baghdad, 2010.

[7] K. E. Sharquie, A. A. Noaimi and M. S. Al-Zoubaidi, "Treatment of Basal Cell Carcinoma by Topical 25\% Podophyllin Solution," Thesis, Iraqi Board for Medical Specializations in Dermatology and Venereology, Baghdad, 2012

[8] K. E. Sharquie and A. A. Noaimi, "Basal Cell Carcinoma: Topical Therapy versus Surgical Treatment," JSSDS, Vol. 16, No. 2, 2012, pp. 41-51.

[9] K. E. Sharquie and L. H. Al-Taha, "Podophyllin (25\%) as a Topical Therapy for Genital Warts in Pregnant Women," Medical City \& College of Medicine-Baghdad Joint Conference, Baghdad, 24 December 2012.

[10] K. E. Sharquie, A. A. Noaimi and W. K. Al-Janabi, "Efficacy and Safety of Topical Podophyllin 5\% Ointment in Patients with Mild Plaque-Type Psoriasis," The Iraqi Postgraduate Medical Journal, Vol. 12, No. 2, 2012, pp. 251-258.

[11] C. S. Carlin, S. R. Feldman, J. G. Kruger, A. Menter and G. G. Krueger, "A 50\% Reduction in Psoriasis Area and Severity Index (PASI) Is a Clinical Significant End Point in the Assessment of Psoriasis," Journal of the American Academy of Dermatology, Vol. 53, No. 6, 2005, pp. 547551.

[12] K. I. Al-Hamdi and L. Al-Kinani, "Treatment of Psoriasis with Zinc Sulphate Cream $2.5 \%$ in Comparison with Clobetasol Propionate Cream," Thesis, Iraqi Board for Medical Specializations in Dermatology and Venereology, Baghdad, 2006.

[13] K. B. Gordan, T. Rolstad and G. Krueger, "Definitions of Measures of Effect Duration for Psoriasis Treatments," Archives of Dermatology, Vol. 141, No. 1, 2005, pp. 8284. http://dx.doi.org/10.1001/archderm.141.1.82

[14] J. C. Sterling, "Virus Infections," In: T. Burns, S. Breathnach, N. Cox and C. Griffiths, Eds., Rook's Textbook of Dermatology, 8th Edition, Wiley-Blackwell Publishing Company, Singapore, 2010, pp. 1489-1566.

[15] United State Pharmacopeia Committees, "Podophyllin," 
In: Drug Information for the Health Care Professional, $24^{\text {th }}$ Edition, Rev. US Convention Inc., Thomason Micromedex, 2004, pp. 2341-2348.

[16] W. G. Douglas, Y. Poulin and J. Decroix, "A New Calcipotriol/Betamethasone Formulation with Rapid Onset of Action Was Superior to Monotherapy with Betamethasone Diproprionate or Calcipotriol in Psoriasis Vulgaris," Acta Dermatovenerologica Croatica, Vol. 82, No. 2, 2002, pp. 131-135.

[17] G. L. Colombo, S. Di Matteo, G. Bruno, G. Girolomoni and G. A. Vena, "Calcipotriol and Betamethasone Dipropionate in the Treatment of Mild-to-Moderate Psoriasis: A Cost-Effectiveness Analysis of the Ointment versus Gel Formulation," ClinicoEconomics and Outcomes Research, Vol. 4, 2012, pp. 261-268.

[18] F. Matthew, H. Yolanda and K. Sewon, "Other Topical Medications," In: J. L. Bolognia, J. L. Jorizzo and V. S. Julie, Eds., Dermatology, 3rd Edition, Mosby Elsevier, New Haven, 2012, pp. 2153-2164.

[19] C. R. Darley, W. J. Cunliffe and C. M. Green, "Safety and Efficacy of Calcipotriol Ointment (Dovonex) in Treat- ing Children with Psoriasis Vulgaris," British Journal of Dermatology, Vol. 135, 1996, pp. 390-393. http://dx.doi.org/10.1111/j.1365-2133.1996.tb01501.x

[20] J. B. Jones, “Topical Therapy," In: T. Burns, S. Breathnach, N. Cox and C. Griffiths, Eds., Rook's Textbook of Dermatology, 8th Edition, Wiley-Blackwell Publishing Company, Singapore, 2010, pp. 3841-3892.
[21] M. Prins, O. Q. J. Swinkels and Van de Kerkhof, "The Impact of the Frequency of Short Contact Dithranol Treatmen," European Journal of Dermatology, Vol. 11, No. 3, 2001, pp. 214-218.

[22] J. H. Nassir, "A Comparative Study between Dithranol and Other Topical Modalities in Treatment of Psoriasis," Diploma Thesis, University of Baghdad, Baghdad, 1991.

[23] M. H. Kanzler and D. C. Gorsulowsky, "Efficacy of Topical 5\% Liquor Carbonis Detergens vs. Its Emollient Base in the Treatment of Psoriasis," British Journal of Dermatology, Vol. 29, No. 3, 1993, pp. 310-314. http://dx.doi.org/10.1111/j.1365-2133.1993.tb11852.x

[24] K. E. Sharquie, A. A. Noaimi and A. R. Auda, "Topical Therapy of Psoriasis by Using 5\% and 10\% Zinc Sulphate," Thesis, Iraqi Board for Medical Specializations in Dermatology and Venereology, 2009.

[25] G. D. Weinstein, "Tazarotene Gel: Efficacy and Safety in Plaque Psoriasis," Journal of the American Academy of Dermatology, Vol. 37, 1997, pp. S33-S8.

[26] G. G. Krueger, L. A. Drake and P. M. Elias, "The Safety and Efficacy of Tazarotene Gel, a Topical Acetylenic Retinoid, in the Treatment of Psoriasis," Archives of Dermatology, Vol. 134, No. 1, 1998, pp. 57-60. http://dx.doi.org/10.1001/archderm.134.1.57 